\begin{tabular}{l}
\multicolumn{1}{c}{$\begin{array}{c}\text { APPLICATION FOR FFI MEMBERSHIP } \\
\text { Please complete in block letters }\end{array}$} \\
Name \\
Address
\end{tabular}

\title{
METHODS OF PAYMENT
}

\section{CHEQUE/ POSTAL OR MONEY ORDER/ GIRO CREDIT (Currency: $£$ sterling only)}

I enclose

$£$

2. CREDIT CARD (AmEx, Visa, Delta, Switch, Access - only for overseas payments)

Name of card

Name of card holder

Card No.

Expiry date

3. BANKER'S ORDER Please send to the FFI, not to your bank.

Name

Account No.

Bank Sort Code

Name and address of bank

Please pay for the credit of Fauna and Flora Preservation Society, Account No. 60336130,

Barclays Bank plc (20-12-75), 139/142 North Street, Brighton BN1 1RU

my subscription of $E \ldots \ldots \ldots \ldots . . .$. due on and the same amount on the same day each

year until further notice.

Signature

This cancels any previous order in favour of the FFPS.

\section{DEED OF COVENANT}

If you pay income tax in the UK you can greatly increase the value of your subscription to the FFI, at no additional cost to yourself, by signing this Deed of Covenant.

I (full name)

of

hereby covenant with the Fauna and Flora Preservation Society, whose office is Great Eastern House, Tenison Road, Cambridge CB1 2DT, that for a period of four years from the date hereof, or until my death (whichever shall be the shorter period) I will pay annually to the said Society from the day of............... (this date should be later than the date of the signature) in every year such a sum as, after deduction of income tax at the standard rate for the time being in force, amounts

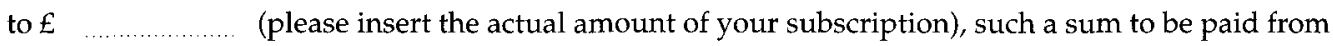
my general fund of taxed income.

Signed and sealed by me this ........... * day of Signature

In the presence of

(signature of witness, who should not be your spouse)

Address

* The first payment must be received within 1 year from this date. 


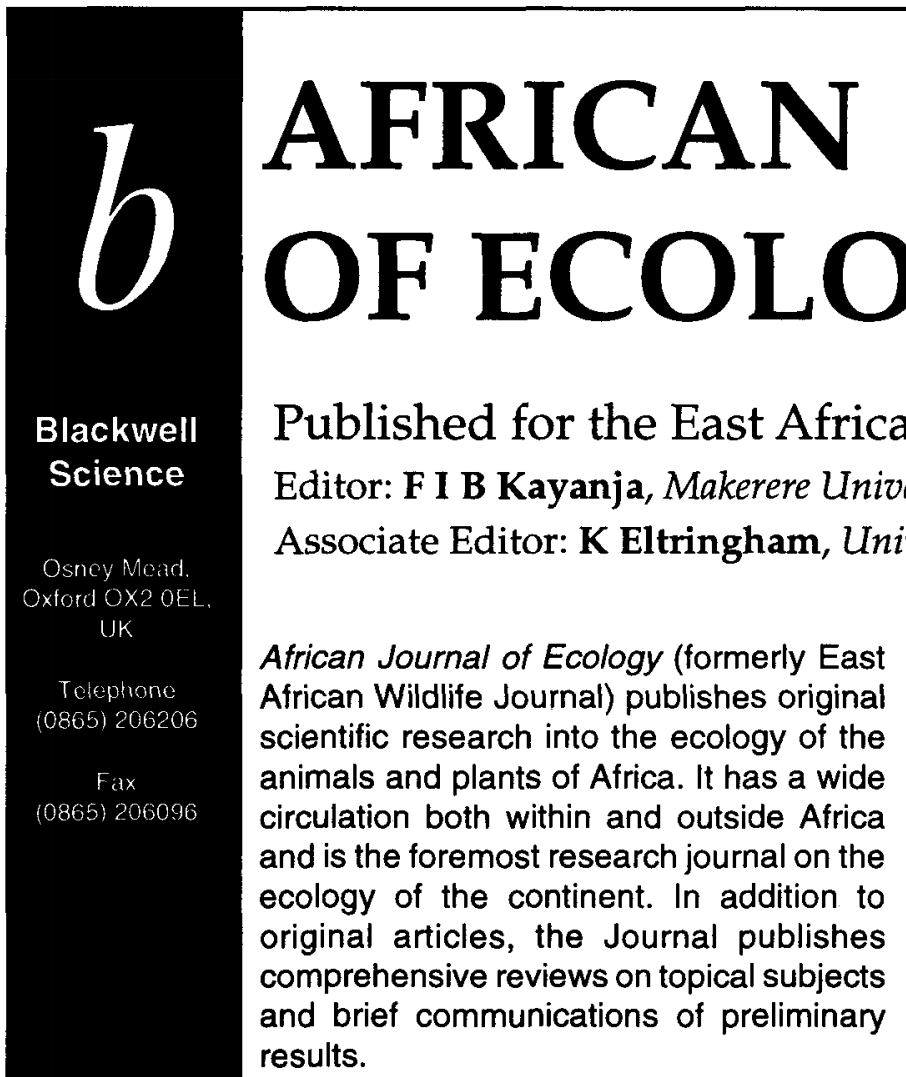
Subscription Information
African Journal of Ecology is published quarterly. Subscription rates for 1996 are $£ 179.50$ (Europe), $£ 198.00$ (overseas), US $\$ 319.00$ (USA \& Canada), post free.
African Journal of Ecology is available on CD-ROM through EcoFile.

\section{Order Form}

Please return to Karen Edge at the address opposite:

$\square$ I would like to subscribe to African Journal of Ecology

$\square$ I wish to pay by cheque and enclose the sum of $\varepsilon$ US\$

$\square$ I wish to pay by Access/American Express/Barclaycard/Diners Card/VISA/Mastercard (delete as necessary). Please debit my credit card number:

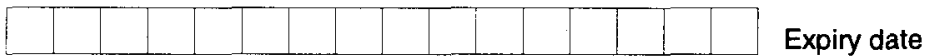

with the sum of $£$ US\$ Signature Date

\section{European Community VAT \& Canadian GST}

Subscribers in Europe must quote their VAT registration number or state that they are not VAT-registered. Subscribers in the following countries who are not VAT-registered must add VAT to the subscription price at the appropriate rate: Belgium (6\% TVA/BTW); France $(2.1 \%$ TVA); Germany ( $7 \% \mathrm{MwSt})$; Spain ( $4 \%$ IVA); The Netherlands ( $6 \%$ BTW).

All subscribers in Canada must add $7 \%$ to allow for GST.

VAT registration number I am not registered for VAT

Please send me a specimen copy of African Journal of Ecology

Please send me more information about EcoFile

Name

Address

worldwide web: http://www.blacksci.co.uk 


\section{A Journal of the British Ecological Society}

\section{Blackwell}

Science

Osncy Mead.

Oxford OXe OEL

UK

Telephone

$101865) 206206$

Fax

$101865) 206096$

\author{
Editors: Bryan Shorrocks, University of Leeds \& Steve Albon, Zoological \\ Society of London
}

The Journal of Animal Ecology first appeared in 1932. It publishes the best in original research on any aspect of animal ecology. Recently it has published papers on population ecology, behavioural ecology, community ecology, physiological ecology and evolutionary ecology. Field, laboratory and theoretical studies based upon terrestrial, freshwater or marine systems are all published. The editors are keen to promote all these traditional areas and in addition would like to see an increasing number of papers in the field of molecular ecology.

The journal presently uses a data-base of 280 international referees to review manuscripts and has an average time to first decision of 6 weeks, and an average of 8 months between revision and

\section{Subscription Information}

Journal of Animal Ecology is published bimonthly. Subscription prices for 1996 are $£ 215.00$ (Europe), £236.00 (Overseas) and US $\$ 380.00$ (North America). Members of the British Ecological Society can receive the journal at a greatly reduced rate, and should contact the Society for details.

Journal of Animal Ecology is available on CDROM through EcoFile. publication.

\section{Order Form}

Please tick the appropriate box and return to Karen Edge at the address opposite:

I would like to subscribe to Journal of Animal Ecology

$I$ wish to pay by cheque and enclose the sum of $f$ US\$

I wish to pay by Access/American Express/Barclaycard/Diners Card/VISA/Mastercard (delete as necessary). Please debit my credit card number:

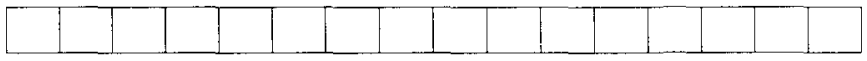

with the sum of $£$

US\$

Signature

Expiry date Date

\section{European Community VAT \& Canadian GST}

Subscribers in Europe must quote their VAT registration number or state that they are not VAT-registered. Subscribers in the following countries who are not VAT-registered must add VAT to the subscription price at the appropriate rate: Belgium ( $6 \%$ TVA $/ B T W)$; France ( $21 \%$ TVA), Germany ( $\%$ MwSt), Spain ( $4 \%$ IVA); The Netherlands ( $6 \%$ BTW).

All subscribers in Canada must add $7 \%$ to allow for GST.

VAT registration number I am not registered for VAT

Please send me a specimen copy of Journal of Animal Ecology

Please send me more information about EcoFile

Name

Address 
General Oryx publishes original articles and reports dealing with the conservation of species and habitats world-wide, with particular emphasis on those that are endangered. All submissions are reviewed by at least two referees. It is helpful if authors suggest at least one referee who is qualified to judge the work objectively.

Submissions should be sent to the Editor, FFI, Great Eastern House, Tenison Road, Cambridge CB1 2DT, UK.

After acceptance papers may be edited to enhance clarity. Where major changes have been made edited manuscripts are returned to authors before type-setting. Page proofs are sent to all authors for approval before going to press. Contributors receive two free copies of the journal and will be entitled to buy additional copies at $£ 2.00$ each, post free. Offprints may be ordered at cost price.

Contributions should be concise but informative, normally in English. Articles should be as short as possible, preferably under 3000 words, and very short articles are acceptable.

Manuscripts should be typed on one side only and double-spaced on A4 paper $(208 \times 298$ $\mathrm{mm})$. The left-hand margin must be at least 40 $\mathrm{mm}$ wide. Two copies should be submitted and authors are also invited to submit papers on disk (IBM compatible or Apple format).

Footnotes should be avoided but, if necessary, should be indicated with asterisks in the text. The author's name and postal address should follow any acknowledgements and references at the end of the article.

References in the text should give the author's name with the year of publication in parentheses. The reference list should be in alphabetical order and include the full article title.

References should be given according to the abbreviations in the World List of Scientific Periodicals. Thus:

Aveling, C. and Harcourt, A.H. 1984. A census of the Virunga gorillas. Oryx, 18, 8-13.

Hartshorn, M.G. 1983. Wildlife conservation in Central America. In Tropical Rain Forest: Ecology and Management (eds S. L. Sutton, T. C. Whitmore and A. C. Chadwick), pp. 421-423. Blackwell Scientific Publications, Oxford.

Illustrations are welcomed and ideally should be glossy, black-and-white whole-plate prints. Good colour slides are acceptable if black-andwhite photographs are not available.

Line drawings and maps should be in black ink on strong white or translucent paper. Lettering on maps and figures should be sent on a separate copy of the figure along with the unlabelled original.

Captions for figures should be typed consecutively on a separate sheet.

Tables. Each table should be self-explanatory and typed on a separate sheet with an appropriate caption.

Scientific names should be underlined and not placed in parentheses. Species' names should follow a checklist, which should be mentioned in a covering letter where there is a risk of confusion.

The first time a species is mentioned its scientific name should be given. English names should be in lower case throughout except where they incorporate a proper name. 


\section{Oryx}

\section{Contents}

Cover

Cover

Irian Jaya, Indonesia

(Alain Compost/Bruce Coleman Ltd)

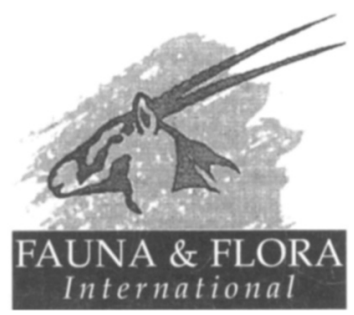

Typesetting and composition by J. Morris

\section{Volume 30 Number 1 January 1996}

Editorial 1

- What makes a conservationist?

Savannah Perspective 2

- Young wisdom

News and Views 4

- The ibex in Saudi Arabia - Tiger-human conflict in southeastern Tibet • SSC Plants Programme news • Trade in seahorses and sea moths booms - Kenya rethinks wildlife policy

Briefly 9

Threatened amphibians in the former Soviet Union: the current situation and the main threats

Sergius L. Kuzmin 24

The impact of selective logging on sympatric civet species in Borneo

Matthew J. Heydon and Pullin Bulloh $\mathbf{3 1}$

Preliminary assessment of large mammals in the

Namcha Barwa region of south-eastern Tibet

Qiu Ming Jiang and William V. Bleisch 37

The mountain tapir, endangered 'flagship' species of the high Andes

Craig C. Downer 45

Exploitation of megapode eggs in Indonesia: the role of traditional methods in the conservation of megapodes Marc Argeloo and René W. R. J. Dekker 59

Ecotourism in the Tangkoko DuaSudara Nature Reserve: opening Pandora's box?

Margaret F. Kinnaird and Timothy G. O'Brien 65

Primates of the Cantanhez Forest and the Cacine Basin, Guinea-Bissau

Spartaco Gippoliti and Giacomo Dell'Omo 74

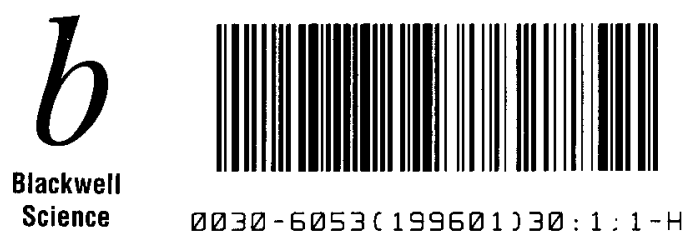

Printed by Thanet Press Limited, Margate, Kent 